Sciensage

Journal of Advanced Scientific Research

Available online through https: / /sciensage.info
ISSN: 0976-9595

Research Article

DOI: $10.55218 /$ JASR. 202213143

\title{
GREEN SYNTHESIS AND CHARACTERIZATION OF SILVER NANOPARTICLES USING HELIOTROPIUM INDICUM L. LEAVES EXTRACT AND ANTIMICROBIAL ACTIVITY
}

\author{
Mini Gopinathan $*^{1}$, M. Balasubramanian ${ }^{2}$ \\ ${ }^{1}$ Department of Biotechnology and Research, KVM College of Science and Technology, Kokkothamangalam \\ P.O, Cherthala, Kerala, India \\ ${ }^{2}$ Department of Biotechnology, Vivekanandha College of Arts and Sciences for Women (Autonomous) Tiruchengode, Namakkal (dt), \\ Tamil Nadu, India \\ *Corresponding author: minigopinathan1970@gmail.com
}

\begin{abstract}
Silver is known for its antimicrobial effects and silver nanoparticles have become a promising synthetic strategy due to its antimicrobial potential. The study was carried out in Heliotropium indicum L. aqueous leaves extract for determining the antimicrobial activity of silver nanoparticles (AgNPs) against human skin pathogens with statistical tests at $1 \%$ level of significance. Characterization of AgNPs was carried out by UV-Vis Spectroscopy, X-ray Diffraction Spectroscopy (XRD) and Scanning Electron Microscopy (SEM). Antimicrobial activities of AgNPs was determined by agar well diffusion method and MIC was determined by resazurin-based turbidometric method. The UV spectroscopic analysis showed the highest absorbance peak at $420 \mathrm{~nm}$. The particle size and structure was confirmed by SEM analysis and it was revealed that the formed particles were of different shapes but predominantly spherical with an average size of 77-98 nm with interparticle distance. The crystalline nature of the AgNPs was determined by X-ray diffraction patterns. The biosynthesized AgNPs exhibited excellent antibacterial activity against Pseudomonas aeruginosa (MTCC 4676) and antifungal activity against Candida albicans (MTCC 183). Kolmogorov-Smirnov and Shapiro-Wilks test, Levene's test of homogeneity of variance and ANOVA were performed using SPSS software. The ANOVA test revealed that the zone of inhibition against $P$. aeruginosa, $S$. aureus, B. cereus, $T$. rubrum and $C$. albicans was significantly different among samples at $1 \%$ level of significance $(\mathrm{p}<0.01)$. The potent antimicrobial activity may justify the biomedical use of AgNPs as antimicrobial agents for controlling microbial infections.
\end{abstract}

Keywords: Heliotropium indicum L., Green synthesis, Antimicrobial, SEM, XRD, Resazurin.

\section{INTRODUCTION}

India is a rich source of medicinal and aromatic plants. Medicinal plants and their therapeutic values are used to effectively treat human diseases all over the world. Heliotropium indicum L. or "Indian heliotrope", which is native to Asia and found throughout India, is an annual herbaceous weed under the family Boraginaceae. Majority of plants belonging to the family, Boraginaceae are herbs. Most of the heliotropes are popular garden plants and some others occur as weed. Many plants that are widely accepted as weeds are also grown in gardens and other cultivated areas; these are known as beneficial weeds [1]. It is known as "Thekkida"or "Venal pacha" in Kerala. This plant was authenticated at Botanical Survey of India, Coimbatore, India as Heliotropium indicum L. (Boraginaceae) and the herbarium is stored at BSI, Coimbatore (BSI/SRC/5/23/2018/Tech/412) [2].
Heliotropium indicum L. possess phytochemicals which includes pyrrolizidine alkaloids, indicine-N-Oxide, tannins, saponins and heliotrine. Indicine-N-Oxide shows no marked hepatotoxicity but it possesses significant antitumour activity. Different extracts of Heliotropium indicum have been studied for possible biological activities in various animal models and reported to possess significant antimicrobial, antifertility, anti-tumor, anti-tuberculosis, anti-inflammatory, histogastroprotective, anti-cataract, analgesic and wound healing activities [3].

Nowadays, the increasing occurrence of microbial infections, rapid emergence of multi-drug resistant strains to recent antibiotics and quick evolution by mutations require development or modification of antimicrobial compounds and alternative treatments [4]. Nanoparticle research has grown into one of the most 
important areas in present day science within a short period [5]. Nanoparticles possess very high surface to volume ratios and exhibit high dispersion and crystallographic surface structure, and displays strong biomedical properties like antimicrobial, anticancer, antidiabetic, antioxidant and anti- inflammatory. The physico-chemical, optical and electronic properties of nanomaterials depend on the size, shape, and surface morphology of nanoparticles. When compared to the other metal nanoparticles, silver nanoparticles (AgNPs) have gained much importance due to the surface plasmon resonance (SPR) (strong absorption in the visible region), which can be easily measured by UVvisible spectrophotometry [6]. Silver and its derivatives are the most potent antimicrobial agents available in therapeutic and preventative health care system. The exact mechanism of action of silver nanoparticles to fight against pathogens is unknown but different authors have proposed different mechanisms according to their findings. One study explains that the antimicrobial property of the silver is associated with the positive charge on the silver $\left(\mathrm{Ag}^{+}\right)$. The positive charge on the surface of the silver nanoparticles could interact with the negative charge on the plasma cell membrane and the nucleic acid which results in the destabilization of the cell membrane and production of ROS and the breakdown of DNA. The $\mathrm{Ag}^{+}$also have abilities to interact with the thiol group (-SH group) of enzyme active sites which results in the formation of the stable complex (Ag-S) and block the enzyme's active site which results in cell death due to the poor respiration [7].

To overcome the complication of toxicity in the synthesis and biological applications, plants or plant extracts have been established to have a leading role in the AgNPs biosynthesis process. Various chemical constituents/phyto-molecules have both protective and reductive activities which are mainly important for the reduction of silver ions adopting natural compounds and reductive enzyme complexes. In recent years, extracellular AgNPs were synthesized using different plant extracts as a potential reducing agent [8].

The current study aimed to evaluate the antibacterial and antifungal activities of biosynthesized silver nanoparticles of $H$. indicum L. leaves extract against bacterial and fungal pathogens. This study provided better statistical report in terms of antimicrobial activity and green synthesis of AgNPs from Heliotropium indicum L. aqueous leaves extract which have enormous future prospects for pharmaceutical industries.

\section{MATERIAL AND METHODS}

\subsection{Leaf sample collection}

The plant Heliotropium indicum L. was collected from a barren paddy field in Cherthala, Kerala, India during the month of May, 2019. The leaves of the plant were washed in water and shade dried for two weeks. The dried leaves were then powdered and kept in air tight container for analysis.

\subsection{Preparation of Leaf Extract}

Aqueous leaf extract was prepared by following reported procedure [9]. Fresh leaves were collected and washed with tap water at first, and then the surface was washed under running water with distilled water until no impurities remained. Then, the fresh leaves were cut into small pieces, and $10 \mathrm{gm}$ was weighed and put into a beaker with $100 \mathrm{ml}$ of distilled water. The mixture was heated for $30 \mathrm{~min}$ at $60^{\circ} \mathrm{C}$ while stirring occasionally and then allowed to cool at room temperature. The mixture was filtered and then centrifuged at $7000 \mathrm{rpm}$ for $10 \mathrm{~min}$ to make it mucilage free. The supernatant was collected and stored in the refrigerator for further use to synthesize $\mathrm{Ag}$ nanoparticles from $\mathrm{AgNO}_{3}$ precursor solution.

\subsection{Biosynthesis and separation of silver nanoparticles}

The AgNPs was synthesized following the reported method [10]. $1 \mathrm{mM}$ of aqueous solution of silver nitrate $\left(\mathrm{AgNO}_{3}\right)$ was prepared and used for the synthesis of silver nanoparticles. $20 \mathrm{ml}$ of leaf extract was added to $100 \mathrm{ml}$ of $1 \mathrm{mM} \mathrm{AgNO} 3$ solution for bioreduction process. The flask was wrapped with an aluminium foil and was then heated in a waterbath at $80^{\circ} \mathrm{C}$ for $3 \mathrm{hrs}$. The setup was incubated in a dark chamber to minimize photo-activation of silver nitrate at room temperature. Reduction of $\mathrm{Ag}^{+}$to $\mathrm{Ag}^{\circ} \mathrm{Nps}$ was confirmed by the colour change of solution from colourless to brown. The synthesized silver nanoparticles were separated by centrifugation according to the method [11]. The solution was centrifuged at $10,000 \mathrm{rpm}$ for $15 \mathrm{~min}$ at $4^{\circ} \mathrm{C}$ and redispersed in distilled water to remove any unbound phytochemicals. Finally, the solution was concentrated using a rotary evaporator and dried.

\subsection{Characterization and analysis of AgNPs} 2.4.1. Ultraviolet-visible spectrophotometer analysis UV-vis spectroscopy; a simple and effective technique to confirm the formation of nanoparticles was performed according to the procedure reported [12]. 
The formation of the reduced silver nanoparticles in colloidal solution was monitored by using a UV-vis spectrophotometer (Shimadzu-UV 1900-i). $4 \mathrm{ml}$ of the diluted AgNPs sample was placed in a cuvette and inserted into the UV-vis spectrophotometer to obtain the UV-vis spectrum of the sample in the wavelength range of 300 and $600 \mathrm{~nm}$ and deionized water was used as the blank.

\subsubsection{Scanning electron microscopy (SEM) analysis} SEM analysis was done according to the procedure reported [13]. SEM investigation was done using a scanning electron microscope (Model: JEOL, JSM6390LV, Tokyo, Japan) for the determination of shape and size of formed nanoparticles. A small piece of extrudate of $10 \mathrm{~mm}$ diameter was mounted on specimen stubs using carbon tape and was over coated with gold using JFC 1600. This ion sputtering device performs rapid and efficient gold coating on microscopic specimen, allowing surface visualization. The SEM measurements were performed at $20 \mathrm{kV}$ accelerating voltage. Different magnifications were used as indicated on the images.

\subsection{3. $X$-ray diffraction (XRD) dimension}

The crystallographic structure of purified AgNPs was detected using an XRD spectrum according to the procedure [14]. The sample was smeared over low back ground sample holder (amorphous silica holder) and fixed on the sample stage in goniometer. The instrument (Bruker Model D8 Advance) was set with B$B$ geometry. The current and voltage was set to $40 \mathrm{mV}$ and $35 \mathrm{~mA}$ and data has been collected. The diffracted intensities were recorded from 200 to 800 at 2 theta angles. The average crystalline size of the silver nanoparticles was estimated using the Debye-Scherrer's equation.

\subsection{Antibacterial activity using AgNps}

The synthesized AgNPs of $H$. Indicum L. aqueous extract was tested for antibacterial activity by agar well diffusion method against one Gram negative and two Gram positive bacteria namely Pseudomonas aeruginosa (MTCC 4676), Staphylococcus aureus (MTCC 96) and Bacillus cereus (MTCC 430). Resasurin-based turbidmetric assay and minimum inhibitory concentration (MIC) determination was also performed.

\subsubsection{Agar well-diffusion method}

Nanoparticles were dissolved in distilled water at a concentration of $50 \mathrm{mg} / \mathrm{ml}$. Antibacterial activity was determined by agar well diffusion method [15]. Inoculum containing bacterial culture with 1 O.D (Optical density), to be tested was spread on MullerHinton agar plates with a sterile swab moistened with the bacterial suspension. Subsequently, wells of $8 \mathrm{~mm}$ diameter were punched into the agar medium and using a micropipette, the aqueous extract $(50 \mathrm{mg} / \mathrm{ml})$, silver nanoparticles suspended in distilled water $(50 \mathrm{mg} / \mathrm{ml})$ were loaded at a concentration of $100 \mu \mathrm{l}$ and allowed to diffuse at room temperature for $2 \mathrm{hr}$. The plates were then incubated in the upright position at $37^{\circ} \mathrm{C}$ for $24-$ $48 \mathrm{hr}$. Gentamycin served as positive control and distilled water as the negative control. After incubation, the diameters of the growth inhibition zones were measured in $\mathrm{mm}$.

\subsubsection{Resazurin-based turbidometric assay and MIC determination}

The MIC was performed in 96-well round bottom microtiter plate using standard broth dilution methods. Broth microdilutions were performed precisely according to the Clinical and Laboratory Standards Institute (CLSI) protocol [16]. The resazurin solution was prepared at $0.02 \%(\mathrm{~W} / \mathrm{V})$. The bacterial inoculums were adjusted to $1 \times 10^{6} \mathrm{CFU} / \mathrm{ml}$. For the MIC test, all the 5 wells in vertical rows were filled with $100 \mu \mathrm{l}$ of Muller Hinton Broth (MHB). Horizontal row 5 contained the highest concentration of AgNPs, while horizontal row 1 contained the lowest concentration. Vertical row 1 contained the aqueous extract, bacterial inoculum and MHB. Vertical rows 2, 3, 4, 5, 6, 7 contained AgNPs, MHB and bacterial inoculum. $100 \mu \mathrm{l}$ of AgNPs stock solution $(500 \mu \mathrm{g} / \mathrm{ml})$ was added and diluted twofold with the bacterial inoculums in $100 \mu \mathrm{l}$ of MHB. Vertical row8 served as the positive control, Gentamycin with MHB and bacterial inoculum and vertical row 9 served as the negative control with $\mathrm{MHB}$ only.

\subsection{Antifungal analysis}

The antifungal effect of biosynthesized AgNPs was examined against the fungal isolates Trichophyton rubrum (MTTC 296) and Candida albicans (MTCC 183) which can cause fungal skin infections. Fungal cells were grown in SDA liquid media at $26^{\circ} \mathrm{C}$ for 5 days, and then cells containing $1 \times 10^{6} \mathrm{CFU} / \mathrm{ml}$ were cultured on fresh SDA solid media. Agar well diffusion method was performed according to the procedure [15]. Wells of 8 $\mathrm{mm}$ diameter were punched into the SDA medium and 
filled with $100 \mu \mathrm{l}$ of nanoparticle synthesized $(50 \mathrm{mg} /$ $\mathrm{ml}$ ) and incubated at $26^{\circ} \mathrm{C}$ for 5 days.

\subsubsection{Resazurin-based turbidometric assay and MIC}

The MIC of the antifungal effect for AgNPs was conducted corresponding to the Clinical and Laboratory Standards Institute (CLSI) protocol [16]. The antifungal activity was evaluated against the fungal concentration of $1 \times 10^{6} \mathrm{CFU} / \mathrm{ml}$. For the MIC test, all the five wells in vertical rows were filled with Sabouraud Dextrose Broth (SDB). Horizontal row 5 contained the highest concentration of AgNPs, while horizontal row 1 contained the lowest concentration. Vertical row 1 contained the aqueous extract, fungal inoculum and SDB. Vertical rows 2-7 contained AgNPs, SDB and fungal inoculum. $100 \mu \mathrm{l}$ of AgNPs stock solution (500 $\mu \mathrm{g} / \mathrm{ml}$ ) was added and diluted twofold with the fungal inoculums in $100 \mu \mathrm{l}$ of SDB. Vertical row 8 served as the positive control, Natamycin with SDB and fungal inoculum and vertical row 9 served as the negative control with SDB only.

\subsection{Statistical Analysis}

The experiments were conducted for the determination of antimicrobial properties of biosynthesized silver nanoparticles. The experimental data were reported as the mean \pm standard deviation (SD) having six replicates $(n=6)$. The diameter of inhibition zones against the selected bacterial pathogens ( $P$. aeruginosa, S. aureus and B. cereus) and fungal pathogens (T. rubrum and C. albicans) among samples are tested for normality using Kolmogorov-Smirnov and Shapiro-Wilks at the 95\% confidence level. Test of homogeneity of variances among samples was performed using Levene's test. The mean difference between the groups were analysed by Analysis of Variance (ANOVA) followed by Duncan's Post hoc multiple comparison test using SPSS software. 'p' values of $p<0.01$ and $p>0.05$ were considered significant.

\section{RESULTS AND DISCUSSION}

\subsection{Biosynthesis and Characterization of AgNps}

Biosynthesis of silver nanoparticles of aqueous extract was initiated when $H$. indicum $\mathrm{L}$. aqueous extract was introduced into $1 \mathrm{mM} \mathrm{AgNO}_{3}$ solution. The gradual colour change of $\mathrm{AgNO}_{3}$ from colourless to yellow and finally to reddish brown indicated the formation of silver nanoparticles as shown in Fig.1. Formation of AgNPs was further confirmed by using UV-visible spectroscopy, scanning electron microscopy and X-ray diffraction studies. Biosynthesis and characterization studies of $H$. indicum L. AgNPs has not reported yet.

\subsection{UV-Visible Spectroscopy}

Formation of the nanoparticles in the aqueous solution was further confirmed by the UV-visible spectroscopy. The wavelength scale was fixed between 360 and $600 \mathrm{~nm}$, and the solution was scanned in this range. Maximum absorbance at $420 \mathrm{~nm}$ was observed, which is characteristic of silver nanoparticles. The UV-vis spectrum (Fig. 1) shows an increase in absorbance with the increase in incubation time $(30 \mathrm{~min}, 45 \mathrm{~min}$, and $1 \mathrm{hr}$ ) of silver nitrate and aqueous extract.

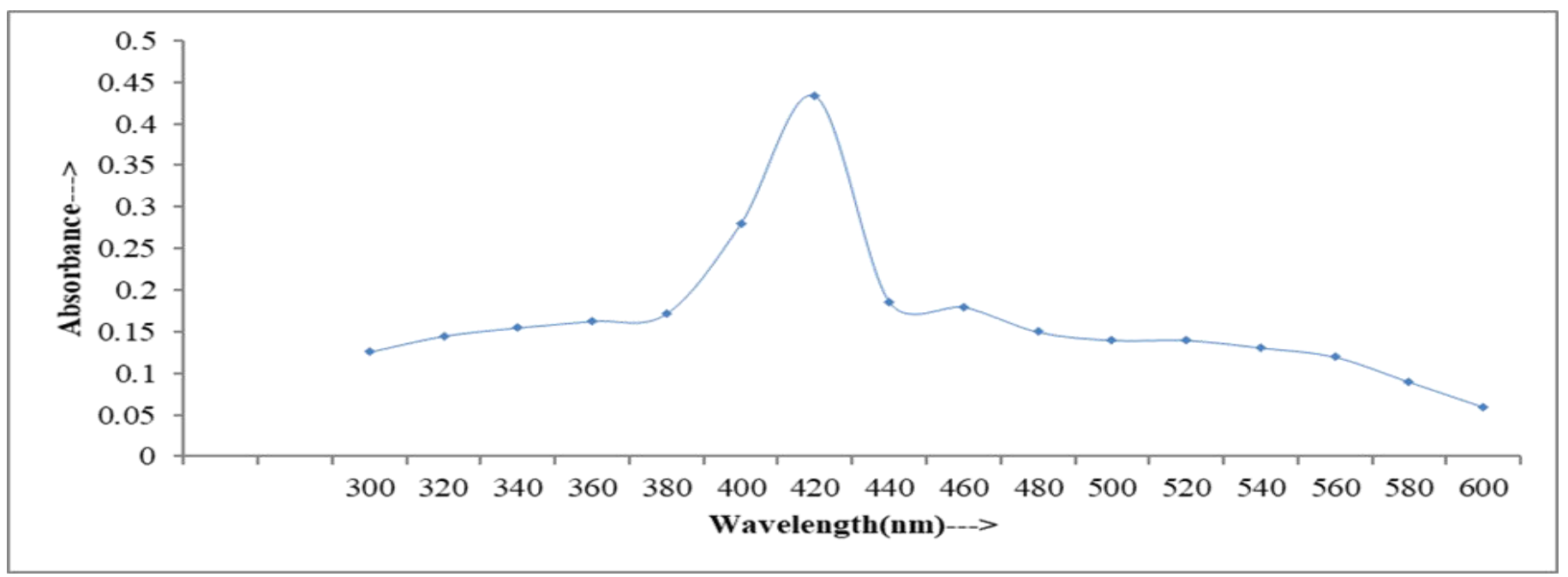

Fig. 1: UV-vis spectrum 


\subsection{Scanning Electron Microscopy [SEM]}

SEM technique was employed to visualize the size and shape of silver nanoparticles. The formation of silver nanoparticles as well as their morphological dimensions in the SEM study demonstrated that the average size was from 77-98 nm with inter-particle distanceas shown in Fig. 2. The shapes of the silver nanoparticles were found to be of different shapes but predominantly spherical.
The SEM image also showed the aggregation of the silver nanoparticles. Formation of silver nanoparticles was due to interactions of hydrogen bond and electrostatic interaction between the biomolecules capping with Ag ions. The nanoparticles were not in direct contact, indicating stabilisation of nanoparticles by capping agent.
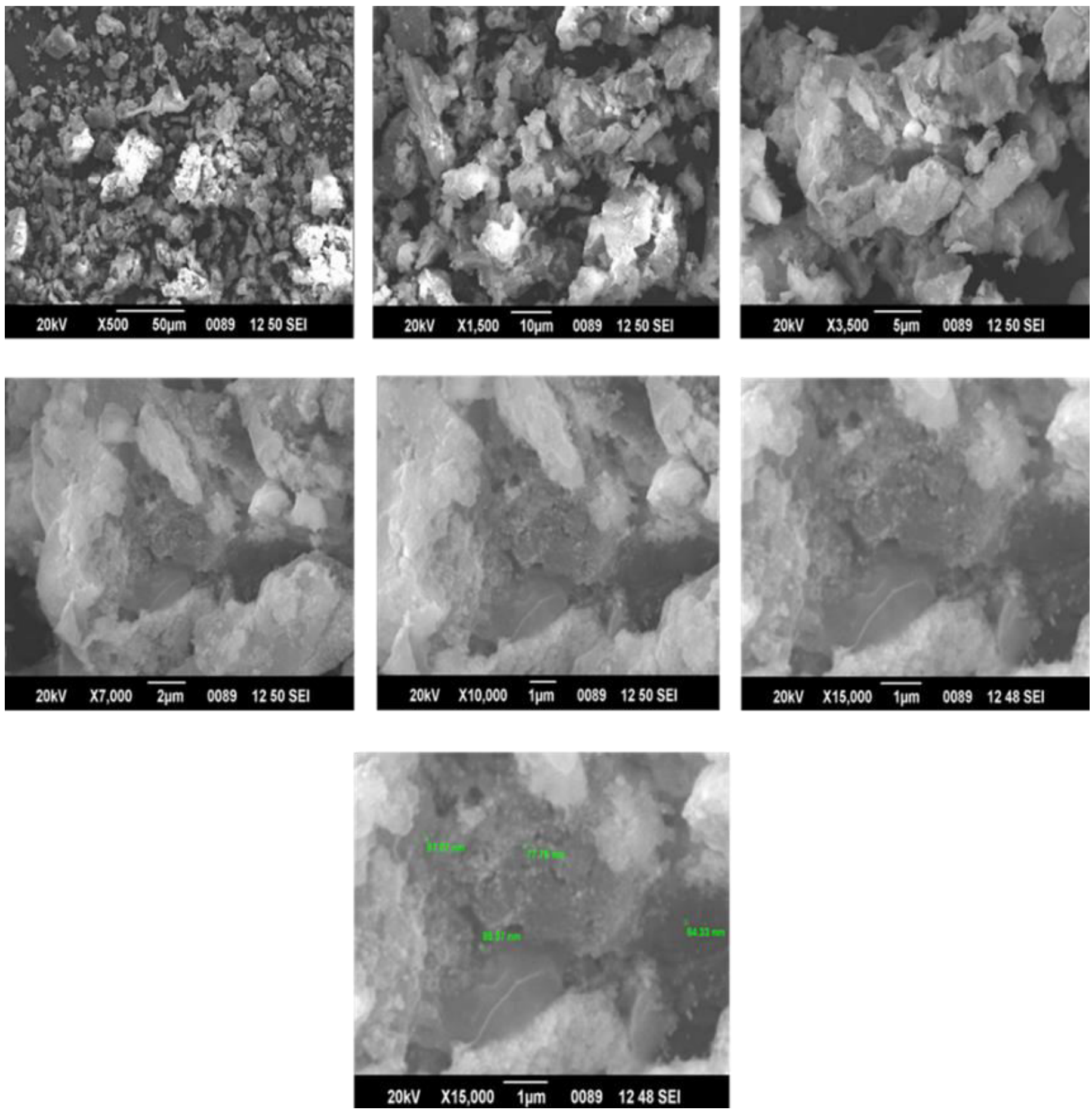

Fig. 2: Scanning electron micrographs of synthesized AgNPs at different magnifications 


\subsection{XRD analysis of biosynthesized silver nanoparticles}

The interplanar spacing values are depicted in Table 1 and the values matched with standard silver values. By determining the width of Bragg's reflection, the estimated average size of the particle falls in the range of $15-18.5 \mathrm{~nm}$.

Fig. 3 shows the XRD pattern of silver nanoparticles which confirmed the crystalline nature of AgNPs. In addition, five unassigned peaks appeared at $27.99^{\circ}$, $32.41^{\circ}, 34.44^{\circ}, 44.50^{\circ}$ and $46.39^{\circ}$. These peaks were weaker than those of silver. This may be due to the bioorganic compounds occurring on the surface of the
AgNPs. Unpredicted crystalline structures are also present and might be due to the organic compounds in the leaf extract. Appearances of these peaks are due to the presence of phytochemical compounds in the leaf extracts. The stronger planes indicate silver as a major constituent in the biosynthesis.

Table 1: The interplanar spacing (dcalculated) values and respective crystal size

\begin{tabular}{ccc}
\hline $2 \theta$ & d Value & Crystal size $(\mathrm{nm})$ \\
\hline $38.289^{\circ}$ & $2.34883 \mathrm{~A}$ & 15.7 \\
\hline $64.642^{\circ}$ & $1.44071 \mathrm{~A}$ & 18.33 \\
\hline $77.576^{\circ}$ & $1.22965 \mathrm{~A}$ & 15.84 \\
\hline
\end{tabular}

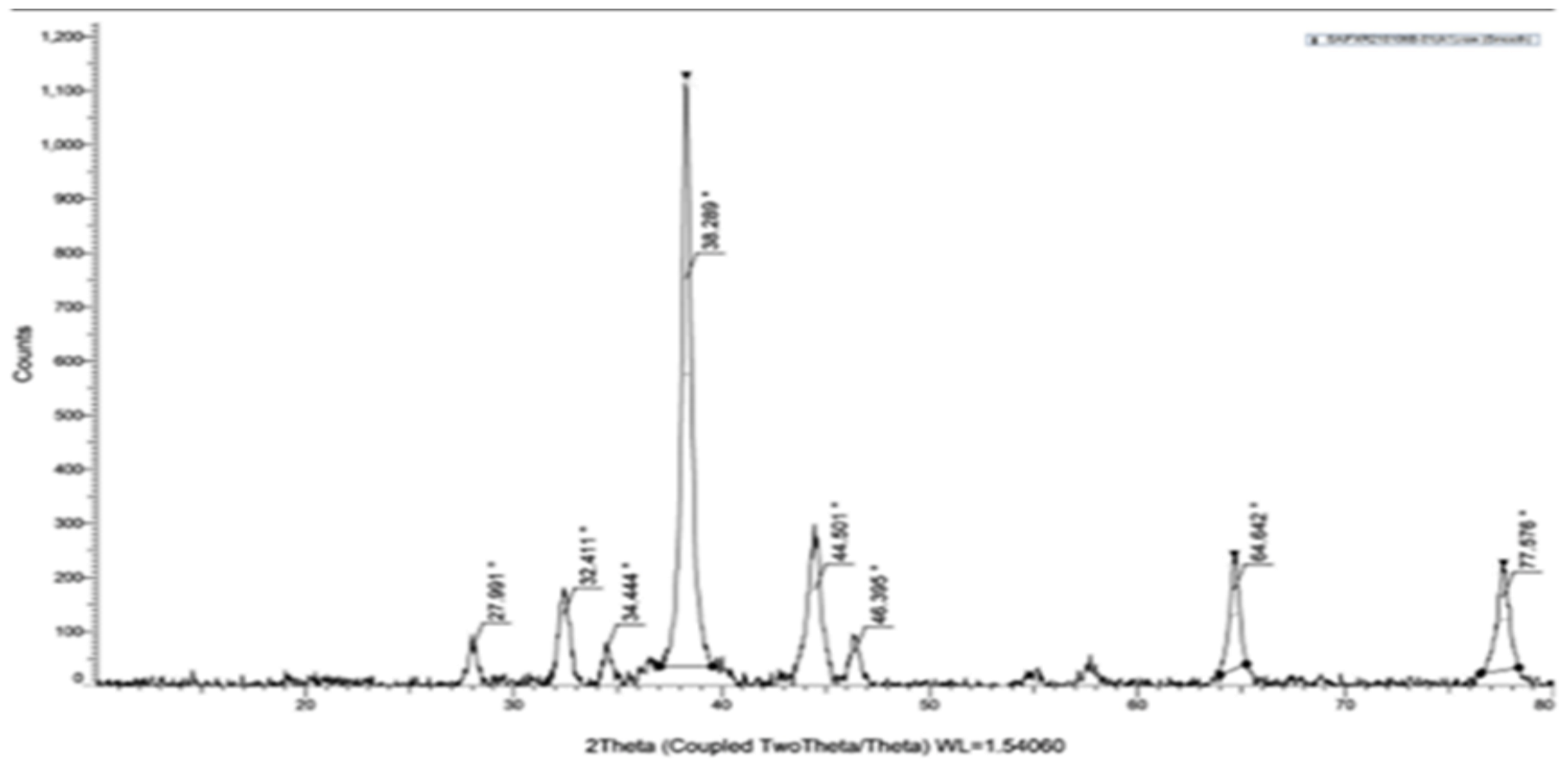

Fig. 3: XRD analysis of biosynhtesized AgNps

\subsection{Antibacterial activity of AgNPs}

The antibacterial activity of AgNPs was determined against one Gram-negative bacteria, $P$. aeruginosa (MTCC 4676) and two Gram-positive bacteria, Staphylococcus aureus (MTCC 96) and Bacillus cereus (MTCC 430). Table 2 shows the diameter of inhibition zones formed and the AgNPs exhibited better antibacterial activity. Fig. 4 shows the formation of inhibition zones around the wells which shows bacterial sensitivity to antibacterial and antibiotic ingredients (which are used as positive controls). The positive control used was gentamycin and functioned as a positive control. On the other hand, distilled water served as the negative control to determine the effects of solvents in the test solution on the growth of $P$. aeruginosa, S. aureus and B. cereus. It was found that it was the extracts containing AgNPs that had the antibacterial activity, not the solvent. The antibacterial activity of AgNPs against Pseudomonas aeruginosa $(24.40 \mathrm{~mm})$ was comparable with that of the standard antibiotic, gentamycin $(26.03 \mathrm{~mm})$ and revealed higher antibacterial activity. The inhibition zone of Bacillus cereus was not comparable with the standard. The zone diameter of AgNPs was greater when compared with the zone diameter of aqueous extract. Green synthesized silver nanoparticles from $H$. indicum L. aqueous leaves extract showed excellent antibacterial activity against $P$. aeruginosa and S.aureus. 
Table 2: Measurement of diameter of zone of inhibition

\begin{tabular}{cccc}
\hline Test samples $(100 \mu \mathrm{l})$ & $\begin{array}{c}\text { Diameterof ZOI against } P . \\
\text { aeruginosa }(\mathrm{mm})\end{array}$ & $\begin{array}{c}\text { Diameter of ZOI } \\
\text { against S.aureus }(\mathrm{mm})\end{array}$ & $\begin{array}{c}\text { Diameter of ZOI against } \\
\text { B. cereus }(\mathrm{mm})\end{array}$ \\
\hline Nanoparticle & 24.40 & 20.08 & 18.9 \\
\hline Aqueous & 14.08 & 12.9 & 11.1 \\
\hline Gentamycin (positive control) & 26.03 & 27.08 & 28 \\
\hline Distilled water (negative control) & 0.00 & 0.00 & 0.00 \\
\hline
\end{tabular}

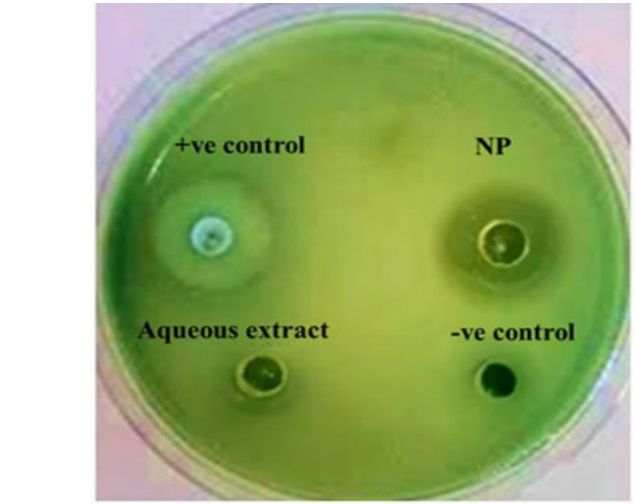

Against P.aeruginosa

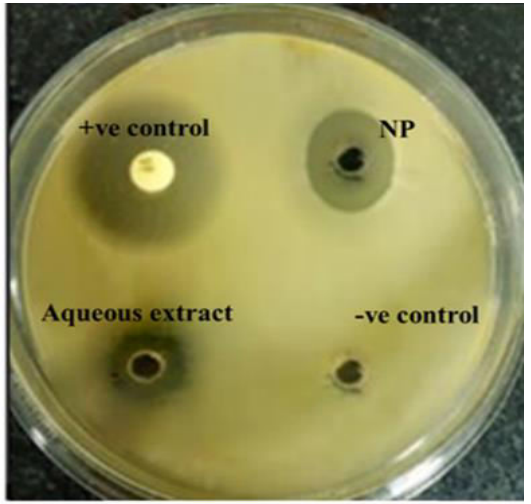

Against S.aureus

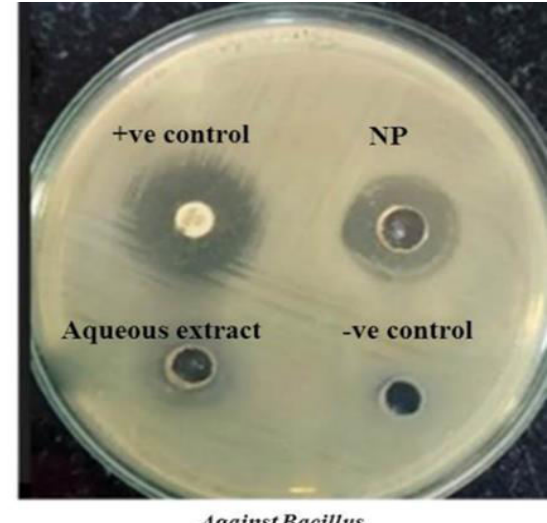

Against Bacillus

'十' control - Gentamycin, '- ' control - distilled water, NP - Nanoparticle

Fig. 4: Antibacterial activity against $P$. aeruginosa, $S$. aureus and $B$. cereus

Alcoholic whole plant extract of Heliotropium indicum has been investigated for its antimicrobial activity against bacterial species like Bacillus subtilis, Bacillus pumilus, Staphylococcus aureus, Micrococcus glutamicus, Pseudomonas aeruginosa, Proteus vulgaris, Serratia marcescens and Escherichia coli [17]. Heliotropium indicum not only showed a dose dependent inhibition against bacterial species but also inhibited fungal species like Aspergillus niger, Aspergillus wentii and Rhizopus oryzae and the yeast, Saccharomyces cerevisiae and Candida albicans. H. indicum L. methanolic leaves extract was effective against Escherichia coli, Pseudomonas aeruginosa, Klebsiella spp, Proteus mirabilis and Staphylococcus aureus at different concentrations and it was found that $S$. aureus and Klebsiella spp. were inhibited at 50, 100 and $200 \mathrm{mg} / \mathrm{ml}$ concentrations with MIC of $3 \mathrm{mg} / \mathrm{ml}$. P. aeruginosa and P. mirabilis were inhibited at $100 \mathrm{mg} / \mathrm{ml}$ and 200 $\mathrm{mg} / \mathrm{ml}$ with MIC of $10 \mathrm{mg} / \mathrm{ml}$ and E. coli was inhibited only at $200 \mathrm{mg} / \mathrm{ml}$ with MIC of $20 \mathrm{mg} / \mathrm{ml} \mathrm{[18].}$ Ethanoic leaf and root extract of $H$. indicum L. was investigated for its antimicrobial activity against six human pathogens and the study revealed that the ethanolic leaf extract possessed higher inhibitory activity when compared to the root extracts and the extract caused dose dependent inhibition against $S$. aureus and $C$. Albicans [19]. GC-MS analysis revealed the presence of terpenes, fatty acids, phytol, alkaloids and organic derivatives in the plant may have contributed to its therapeutic activity. $H$. curassavicum L. exhibited inhibitory activity against Bacillus pumilis, Enterococcus faecalis, Micrococcus luteus, Streptococcus faecalis, Escherichia coli, Klebsiella pneumoniae and Proteus vulgaris [20]. Methanolic extract of whole plant of $H$. curassavicum L also revealed significant antibacterial activity against Pseudomonas aeruginosa, Acetobacter motfi, Enterococcus hirae and Bacillus cereus with highest activity against Pseudomonas aeruginosa [21]. The antimicrobial activity of Heliotropium marifolium Retz. was studied in hexane, chloroform, ethyl acetate methanol and water whole plant extracts which also exhibited significant inhibitory activity against Staphylococcus aureus, Escherichia coli, Pseudomonas aeruginosa, Klebsiella pneumoniae, Salmonella typhii, Proteus mirabilis, Salmonella paratyphii A and Salmonella paratyphii B [22]. Heliotropium bacciferum was studied for its antimicrobial activity in methanol, hexane, ethyl acetate, butanol and aqueous aerial parts extracts showed inhibitory activity against bacterial and fungal strains [23] but no active principles have been isolated. Biosynthesized AgNPs exhibited excellent antibacterial activity against the tested pathogens when compared with $H$. indicum L. aqueous extract and there are no previous reports. 


\subsubsection{Resazurin-based MIC determination}

Agar well diffusion method was described as the preliminary study in screening the antibacterial activity. Therefore, MIC was needed for further evaluation. MIC was defined as the lowest concentration of the antibacterial agent to inhibit the growth of bacteria by serial dilution. The MIC values of AgNPs against the pathogens were ranged from 6.25 to $25 \mathrm{mg} / \mathrm{ml}$. AgNPs inhibited the growth of $P$. aeruginosa (Gram-negative) at a concentration of $6.25 \mathrm{mg} / \mathrm{ml}$ and $S$. aureus and $B$. cereus (Gram positive) at $25 \mathrm{mg} / \mathrm{ml}$. P. aeruginosa showed the MIC value of $6.25 \mu \mathrm{g} / \mathrm{ml}$ which was comparable with the antibiotic, gentamycin.

\subsection{Antifungal activity of $\mathrm{AgNps}$}

The antifungal activity of green synthesized AgNPs against Trichophyton rubrum (MTCC 296) and Candida albicans (MTCC 183) was determined. The aqueous extract and biosynthesized AgNPs exhibited antifungal activity against the selected fungi. The biosynthesized nanoparticles showed better antifungal activity against T. rubrum and C. albicans. Fig 5 shows the presence of clear zone around the AgNPs which suggested better antifungal activity. The antifungal activity of AgNPs against $C$. albicans $(21 \mathrm{~mm})$ was comparable with that of the standard antibiotic, Natamycin $(25.42 \mathrm{~mm})$ and revealed good antifungal activity. The zone diameter of AgNPs was greater when compared with the zone diameter of aqueous extract (Table 3). The results obtained in the present study were comparable with that of earlier reports in polar solvents against the tested organisms. There are no reports on antimicrobial activity of synthesized silver nanoparticles of $H$. indicum L. leaves extract till now and the results obtained from the present antimicrobial activity study indicated that synthesized AgNPs exhibited significant inhibition against $P$. aeruginosa and $C$. albicans when compared with the other test organisms. The antimicrobial activity of leaves extract of $H$. indicum L. against bacterial and fungal pathogens was found promising in earlier reports.

\section{Table 3: Measurement of diameter of zone of inhibition}

\begin{tabular}{ccc}
\hline Test samples $(100 \mu \mathrm{l})$ & Diameter of ZOI against T. rubrum $(\mathrm{mm})$ & Diameter of ZOI against C.albicans $(\mathrm{mm})$ \\
\hline Nanoparticle & 19.95 & 21.00 \\
\hline Aqueous & 15.47 & 13.27 \\
\hline \begin{tabular}{c} 
Gentamycin (positive control) \\
\hline $\begin{array}{c}\text { Distilled water (negative } \\
\text { control) }\end{array}$
\end{tabular} & 23.00 & 25.42 \\
\hline
\end{tabular}

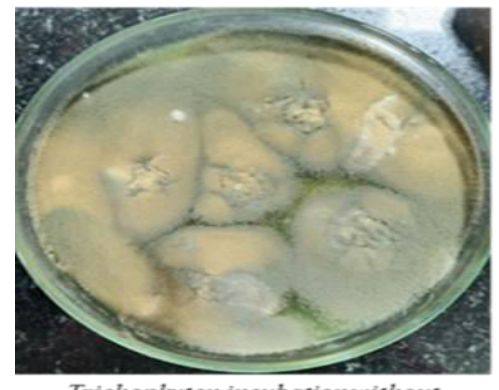

Trichoplyton incubation without AgNPs

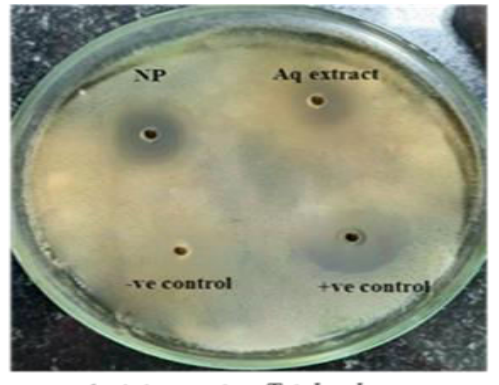

Activity against Trichoplyyton

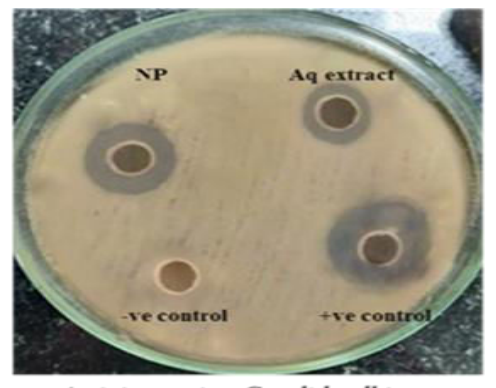

Activity against Candida albicans

'+' control - Natamycin, '- ' control - distilled water, Aq extract - Aqueous extract, NP - Nanoparticle

Fig. 5: Antifungal activity against T. rubrum and C. albicans

\subsubsection{Resazurin based MIC determination}

The MIC values of AgNps against the fungal pathogens were ranged from 6.25 to $25 \mathrm{mg} / \mathrm{ml}$. AgNPs inhibited the growth of $T$. rubrum and $C$. albicans at a concentration of $6.25 \mathrm{mg} / \mathrm{ml}$. Both the pathogenic fungi showed the MIC value of $6.25 \mu \mathrm{g} / \mathrm{ml}$ which was comparable with the antibiotic, Natamycin. Green synthesized silver nanoparticles from $H$. indicum L. aqueous leaves extract showed better antifungal activity against T. rubrum and C. albicans. There are no earlier reports on resazurin based MIC determination in $H$. indicum $\mathrm{L}$ aqueous leaves extract till date.

\subsection{Statistical analysis}

All data were statistically analysed using SPSS software. The data are expressed as mean \pm SD $(n=6)$. The antibacterial and antifungal activity of aqueous leaf extract and AgNPs were analysed by normality tests 
using Kolmogorov-Smirnov and Shapiro-Wilks test, Levene's test of homogeneity of variance and ANOVA for the determination of inhibition zones and MIC. Kolmogorov-Smirnov and Shapiro-Wilks test showed that zone of inhibition values were not significantly deviated from normality $(p>0.05)$. Levene's test indicated no significant difference invariances among all the samples tested $(\mathrm{p}>0.05)$. The ANOVA test showed that the zone of inhibition against $P$. aeruginosa, $S$. aureus, T. rubrum and $C$. albicans was significantly different among samples at $1 \%$ level of significance $(\mathrm{p}<$ 0.01).Statistical studies based on the effect of synthesized silver nanoparticles against bacterial and fungal pathogens in $H$. indicum L. aqueous extract was not reported yet.

\section{CONCLUSION}

The present study demonstrates a simple green synthetic approach for the synthesis of AgNPs using aqueous leaf extract of $H$. Indicum $\mathrm{L}$. as a biological reducing agent. The aqueous leaf extract was found to contain alkaloids, tannins, glycosides, phenols and flavonoids in earlier reports and these compounds effectively act as reducing agents and lead to the synthesis of AgNPs. Colour change, UV-visible spectrum, SEM and XRD assessments supported the biosynthesis and characterization of AgNPs. The synthesized AgNPs was found having potent antimicrobial activities and the study also demonstrates that the antimicrobial AgNPs was synthesized using a weed plant seen in waste lands. Thus, the study has shown that traditionally used andeasily available $H$. indicum L. can be a low-cost source of important bioactive molecules with potential for herbal drug development and nanoparticle synthesis.

\section{ACKNOWLEDGEMENTS}

The authors sincerely acknowledge the lab facilities provided by KVM College of Science and Technology, Cherthala, and DST-SAIF, Cochin, Kerala to do the research work. Authors also acknowledge Botanical Survey of India, Coimbatore for identifying and authenticating the plant material.

\section{Conflict of interest}

None declared

\section{REFERENCES}

1. Ghosh P, Das C, Biswas S, Nag SK, Dutta A, Biswas M et al. F1000Research, 2020; 9(493).
2. Ministry of Environment, Forest and Climate change, Botanical Survey of India, Southern Regional Centre, T. N.A.U. Campus, Lawley Road, Coimbatore, 2018.

3. Chunthorng-Orn J, Dechayont B, Phuaklee P, Prajuabjinda O, Juckmeta T, Itharat, A. J Med Assoc Thai., 2016; 99:S102 - S109.

4. Roy A, Bulut O, Some S, Mandal AK, Yilmaz MD. RSC Advances, 2019; 9(5):2673 - 2702.

5. Alyousef AA, Arshad M, AlAkeel R, Alqasim A. Biotechnol. Biotechnol. Equip., 2019; 33(1): 931-936.

6. Supriya G, Chaitanya kumari S.Int. j. sci. res. biol. sci., 2019; 6(1):60 - 65.

7. Javed B, Nadhman A, Mashwani ZUR.Mater. Res. Express., 2020; 7(8).

8. MohantaYK, Panda SK, Jayabalan R, Sharma N, Bastia AK, Mohanta TK. Front. Mol. Biosci., 2017; 4(3):1-9.

9. Das J, Das MP, Velusamy P. Spectrochim Acta A., 2013; 104:265-270.

10. Shankar SS, Rai A, Ahmad A, Sastry M. Chem. Mater., 2005; 17(3):566 - 572.

11. Dipankar C, Murugan S.Colloids Surf B Biointerfaces., 2012; 98:112-119.

12. Huang J, Li Q, Sun D, Lu Y, Su Y, Yang X. et al. Nanotechnology., 2007; 18(10):105104.

13. Gopinath K, Gowri S, Arumugam A. J. nanostructure chem., 2013; 3(1):1-7.

14. Ajitha B, Reddy YAK, Reddy PS. Mater. Sci. Eng. C., 2015; 49:373-381.

15. Wayne PA.Clinical and Laboratory Standards Institute., 2002.

16. Khalifa RA, Nasser MS, Gomaa AA, Osman NM, Salem HM.Egypt.J.Chest Dis. Tuberc., 2013; 62(2):241-247.

17. Rao PR, Nammi S, Raju ADV. J. Nat. Remedies., 2002; 2(2):195-198.

18. Osungunna M, Adedeji K. J. Microbiol. Antimicrob., 2011; 3(8): 213-216.

19. Ramamurthy V, Nethaji S, Rajakumar R. Glob. j. biol. agric. health sci., 2014; 3(3):261-264.

20. Viswanath K, Prasad KRS, Shanmukh Kumar JV. Res J Pharm Biol Chem Sci., 2014; 5(4):1367-1370.

21. Gokulnath M, Yuvaraj D, Gayathri PK, Chandran M, Vivek P, Kesavan D. Int J Chem Tech Res., 2014; 6(9):4307-4311.

22. Radha R, Lata T, Rajendran NN.J. Nat. Med., 2003; 3(2):208-211.

23. Ahmad S, Ahmad S, Bibi I, AbdEI-Salam NM, Hussain H, Ishaq MS et al. Afr J TraditComplement Altern Med., 2015; 12(2):32-35. 